\title{
Concepções e Práticas Avaliativas no Estágio Supervisionado de Ciências e Biologia
}

Anelize Queiroz Amaral

Tais Regina Cutchma

Débora Daneluz

Kassiana Miguel

Lucas Battisti

Alexandre Augusto Auache Filho

\begin{abstract}
Resumo
Este trabalho faz parte de uma reflexão proposta na disciplina de Estágio Supervisionado do Curso de Licenciatura em Ciências Biológica, de uma universidade pública do Estado do Paraná, Brasil. Esta pesquisa objetivou diagnosticar concepções e práticas avaliativas, no sentido de apontar anseios e dúvidas dos alunos em formação inicial. Para tanto, foi aplicado um questionário para doze acadêmicos e em seguida os dados foram submetidos a uma análise quanti-qualitativa. Os dados analisados evidenciaram que o conceito de avaliação ainda necessita de uma reflexão que ultrapasse a visão de um processo puramente classificatório e burocrático, cujo o instrumento avaliativo mais utilizado é a prova escrita. Verificou-se que, após as discussões no decorrer da disciplina de Estágio Supervisionado sobre as práticas avaliativas utilizadas, esse trabalho colaborou com uma melhor compreensão do processo avaliativo, sugerindo e instigando os futuros professores a reverem algumas concepções e práticas avaliativas em seu dia-a-dia.
\end{abstract}

Palavras-chave: avaliação, estágio supervisionado, ensino de biologia.

\section{Abstract \\ Assessment practices and conceptions Supervised Internship in Science and Biology}

This paper integrates a proposed reflection in the Supervised Teaching Practice subject of Biological Science Course (license to teach modality) from a public University in the Paraná State, Brazil. This research aims to diagnose conceptions and assessment practices, to point out anxieties and doubts of students in initial training. For this purpose, a questionnaire was applied to twelve academics and then the data were exposed to a quantitative and qualitative analysis. The analyzed data showed that the concept of evaluation still needs a reflection that exceed the view of a merely classificatory and bureaucratic process whose unique assessment tool used is the written test. It was found that after the discussions during the subject of Supervised Teaching Practice about assessment practices used, this work contributes to a better understanding of the evaluation process, suggesting and encouraging the 
teachers/professors to review some concepts and assessment practices in their day by day.

Keywords: evaluation; Supervised Teaching Practice;, teaching biology.

\section{Introdução}

Torna-se oportuno salientar que uma das discussões que vem se avolumando na área de ensino de ciências e biologia, diz respeito a avaliação escolar e suas práticas avaliativas, portanto, cabe a nós perguntarmos, como entendemos que deva ser feita a preparação desse futuro profissional para superação de obstáculos referentes a uma avaliação meramente punitiva e burocrática que se mantem enraizada no contexto escolar.

As mudanças na forma de compreender a formação docente têm relação direta com o que se pensa e faz no âmbito da formação. Assim, de uma época em que a preocupação era com o despachar professores com diversas fragilidades relacionadas a sua formação, desenvolveu-se a preocupação com o formar, ação na qual é reconhecida a existência de saberes próprios a estes profissionais (ANDRADE, 2005).

De acordo com Pimenta (1997), é na formação inicial que a construção da identidade profissional do professor começa a se estruturar. Sendo assim, devem ser oferecidas e disponibilizadas aos professores em formação oportunidades para que se apropriem de conhecimentos, habilidades e valores necessários à profissão, possibilitando-lhes (re) construir permanentemente seus saberes-fazeres docentes a partir das necessidades e desafios de sua prática. Desse modo, a formação inicial deve estimular uma perspectiva crítico-reflexiva, que forneça aos professores saberes necessários a sua formação.

Nesse sentido, o mero conhecimento das técnicas e metodologias não bastam, pois é preciso que exista o desejo e a vontade de empregá-los na prática docente. Esta atitude obriga, portanto, a escutar e respeitar diferentes perspectivas, a prestar atenção às alternativas disponíveis, a indagar evidências conflituosas, a procurar várias respostas para a mesma pergunta, a refletir sobre a forma de melhorar o que já existe. Essas situações singulares e complexas podem ser viabilizadas já na formação inicial de professores por meio do estágio supervisionado.

Conforme Lisovski et al., (2006, p. 2) “o período do estágio curricular é fundamental na carreira de qualquer professor, sendo o momento em que os estagiários estão mais sensíveis e receptivos às sugestões de colegas". Diante do exposto, o período de estágio supervisionado torna-se um momento de fundamental importância na carreira do professor, sendo um momento em que os estagiários estão mais receptivos a orientações, além de demonstrarem grandes anseios por contribuições que lhes tragam de certa forma maior confiança. 
No entanto, atuamos em um cenário onde "a responsabilidade pela formação dos professores, sobretudo no ensino médio, é vista como exclusiva das Instituições de Ensino Superior - IES" (TERRAZAN, 2003, p.78). A maioria dos professores regentes de turma das Escolas de Educação Básica - EEB costumam apenas repassar ao estagiário uma lista de conteúdos e normas que devem ser seguidos para o bom andamento das aulas. Agindo assim, eximem-se da tarefa de um acompanhamento mais efetivo dos estagiários, além de não possibilitarem uma troca de saberes essenciais para a formação desses futuros professores.

Outra questão muito importante e que merece atenção especial com vistas à qualidade de ensino surge por conta da sobrecarga de aulas a que os professores regentes de turma são submetidos para garantir sua dignidade. "Este, sobrecarregado pela necessidade de dar muitas aulas, em várias escolas, de atender classes numerosas, é levado a simplificar sua tarefa" (KRASILCHIK, 1980, p. 175). Isso inviabiliza sua atuação de forma significativa na construção de saberes experienciais dos futuros professores, gerando uma formação inadequada às exigências que a prática escolar preconiza hoje.

Em síntese, ambas as instituições citadas envolvem-se de maneira limitada nas discussões sobre a formação de professores e, além disso, falham no que tange a propiciar condições para essa formação. |Nesse sentido, o estágio, que deveria ser um momento de grande aprendizado e reflexão sobre a futura profissão, passa a ser simplesmente um momento de cumprimento dos requisitos para sua certificação profissional.

É preciso que se estabeleça uma troca de experiências entre Instituições de Ensino Superior e Escolas de Educação Básica, para que ocorra o rompimento de concepções como a de que a universidade deve entregar ao mercado de trabalho um professor pronto e acabado, como se fosse um pacote de uma produção.

Diante desses apontamentos, foi proposto aos alunos do $5^{\circ}$ período do curso de Ciências Biológicas - modalidade licenciatura de uma Universidade Pública, um repensar sobre o real sentido do estágio supervisionado e da avaliação no decorrer da disciplina de Estágio Supervisionado de Ciências, momentos de reflexão com a turma no período de regência para trocas de saberes e diálogos com os professores regentes das turmas para uma formação em que a reflexividade se faz inerente ao processo.

\section{Avaliação escolar no processo de formação inicial}

A avaliação escolar é um precioso e imprescindível instrumento para conhecer o que o sistema educativo, desde o estabelecimento de políticas públicas até a realidade das classes, pretende e obtém de seus alunos. Refletir sobre o processo de avaliação escolar é uma maneira de 
compreender o que acontece no ambiente da escola e propor o envolvimento entre a comunidade escolar.

Dentre as várias dimensões da prática docente, a avaliação escolar, ou melhor, a avaliação da aprendizagem e desenvolvimento dos alunos, representa um dos desafios a ser superado pelos futuros professores. Por que desafio? Porque não é fácil romper com a concepção, bastante presente, de que a avaliação configura-se como um processo essencialmente classificatório, punitivo e burocrático.

De acordo com André e Passos (2002, p.177), "quando se avalia através de provas que cobram nomes, datas, ideias copiadas do livro ou do texto está-se dizendo que o principio pedagógico valorizado é o da aprendizagem reprodutiva, baseada na memória e na repetição acrítica das informações".

Quando se pede ao aluno que exponha seu ponto de vista, argumente a favor ou contra uma ideia, produza um texto, participe da elaboração de um projeto, proponha soluções para um problema, esta se acentuando a importância da reflexão e do pensamento investigativo.

De acordo com André e Passos (2002, p.179):

[...] a avaliação deve levar a escola toda a se olhar, a rever seus mecanismos de poder, sua forma de gestão, seus propósitos, suas práticas, as relações que aí se estabelecem. Ao rever suas ações e seus propósitos, a escola terá necessariamente de envolver os pais de alunos e surge então outro âmbito da avaliação, que é o da comunidade escolar ampliada, aqueles que são mais diretamente interessados nos resultados da ação educativa. [...] É imprescindível que os pais participem da elaboração do projeto escolar, que sejam ouvidos, respeitados e chamados a colaborar tanto no desenvolvimento de atividades que levem à concretização das metas do projeto quanto na sua avaliação.

Rompe-se, dessa maneira, com algumas das formas de expressão de poder do professor, o que gera nas escolas um clima de medo e ansiedade entre os alunos impedindo que a sala de aula seja um ambiente prazeroso e de construção.

De acordo com Justina e Ferraz (2009), no processo de ensino e aprendizagem, o professor de Ciências e Biologia, ao planejar e avaliar, confronta-se com uma pluralidade de concepções a respeito do que é ensino, aprendizagem, conhecimento, ciência, entre outros aspectos. Entretanto, ressalta-se que a avaliação, para alguns professores, é um processo que gera dúvidas e insegurança, haja vista o distanciamento entre as recomendações contidas na literatura e sua prática avaliativa, o que inviabiliza o rompimento com uma prática reducionista constituída ao longo dos anos.

Nesse sentido, é provável que a avaliação seja um dos aspectos do processo de ensino e aprendizagem, em que mais se faça necessária uma mudança de concepção e práticas, isto é, um 
trabalho de formação dos professores que questione "o que sempre se fez" e favoreça uma reflexão crítica de práticas docentes muito persistentes.

Tais dificuldades apresentadas mantém-se viva por uma tradição que usa sempre os mesmo tipos de instrumentos, como provas escritas, orais ou práticas e não se vale de outros recursos que possam fornecer conhecimentos e/ou habilidades mais adequadas ao que se pretende verificar.

Portanto, é fundamental que os cursos de licenciatura estejam preparados para apresentar a seus licenciandos os pressupostos teóricos e metodológicos do processo de avaliação escolar, bem como os conflitos e contradições que ainda permeiam as práticas avaliativas, numa perspectiva que eles, durante a sua formação, consigam vivenciar e refletir sobre toda a problemática do processo avaliativo no cotidiano escolar, buscando estratégias e procedimentos avaliativos que superem as práticas tradicionais vigentes.

Com base nestas considerações, a presente pesquisa teve como objetivo investigar as concepções e práticas avaliativas de licenciandos de uma Universidade Pública do Paraná e promover momentos de reflexão sobre a prática docente no decorrer da disciplina de Estágio Supervisionado de Ciências e Biologia. .

\section{Metodologia de pesquisa}

A presente pesquisa contou com a participação de doze licenciandos matriculados no terceiro ano do curso de Licenciatura em Ciências Biológicas, numa Universidade Pública do Paraná. A investigação foi realizada durante a disciplina de Estágio Supervisionado de Ciências e Biologia.

Foram investigadas as concepções dos licenciandos acerca da avaliação escolar, mediante a aplicação de questionário aberto contendo duas questões: a) Para você o que é avaliar? b) Cite instrumentos avaliativos utilizados por você na prática docente.

Esta pesquisa teve em sua análise um caráter quanti-qualitativo, conforme pressupostos de Bogdan e Biklen (1991), a relação estreita entre o pesquisador e a situação onde os fenômenos ocorrem se dá pelo fato de que a ação de analisar e entender fenômenos requerem a compreensão das circunstâncias particulares em que o objeto de análise se insere.

Posteriormente à análise dos resultados, esses foram discutidos com os alunos em Estágio Supervisionado e professores regentes de turma com o objetivo de partilhar, problematizar os aspectos levantados e refletir sobre as concepções e práticas apresentadas no decorrer desse processo formativo. Os relatos feitos pelos alunos foram coletados por meio de gravação e, em seguida, analisados de maneira qualitativa. 


\section{Resultados e Discussões}

Verifica-se que, pela análise da Tabela 1, dos doze acadêmicos, 3 responderam que avaliar significa compreensão do conteúdo; 3 acreditam ser mensurar o conhecimento do aluno; e 6 alunos responderam que avaliar é comprovar o conhecimento, conforme pode ser observado a seguir:

Tabela 1: O que é avaliar

O QUE É AVALIAR

Avaliar é compreensão do conteúdo

Avaliar é mensuração

Avaliar é comprovar o conhecimento

\section{$\mathbf{N}^{\circ}$ alunos}

3

3

6

Os resultados nos levam a concluir que os alunos apresentavam como concepções antes de todo o processo de reflexão realizado o que muitos autores consideram como uma prática reducionista: relacionar a avaliação como um processo exclusivamente de mensuração e comprovação do conhecimento.

Para Krasilchik (1987), o ato de valorizar o processo em lugar de considerar apenas o produto final torna o processo de avaliação mais justo e, portanto, menos suscetível de discordâncias e conflitos.

Segundo Castro e Carvalho (2001), a avaliação dá ao professor informações sobre seu ensino, permitindo-lhe identificar onde seu trabalho deixou de dar resultados esperados, como e onde os estudantes tiveram dificuldades, permitindo que as falhas possam ser reparadas.

Nesse sentido, cabe ressaltar que a avaliação não deve ser entendida como algo que quantifica o aluno ou comprova o seu conhecimento, mas sim como um instrumento que permite ao professor refletir sobre sua prática docente e ao aluno compreender onde está sendo necessário se dedicar mais e juntos buscarem caminhos ainda não percorridos nesse processo formativo.

Para Hoffmann (2001), a avaliação escolar deve ser vista como um processo pedagógico que permite a reflexão tanto do educador quanto a do educando, pois, nessa dimensão educativa, os erros e as dúvidas dos alunos são considerados como momentos importantes a serem considerados pelo professor, no planejamento das ações educativas.

Ao questionar sobre as estratégias ou instrumentos para realizar a avaliação da aprendizagem dos alunos, esses citaram apenas provas escritas e trabalhos escritos de maneira individual.

Revisitando o referência teórico apresentado de acordo com André e Passos (2002, p.177), 
[...] quando se avalia através de provas que cobram nomes, datas, ideias copiadas do livro ou do texto está-se dizendo que o princípio pedagógico valorizado é o da aprendizagem reprodutiva, baseada na memória e na repetição acrítica das informações.

Recorrendo a Justina e Ferraz (2009), a disciplina de Ciências e Biologia não esta isenta de tal realidade. De um lado, o professor que, muitas vezes, concebe a avaliação como um produto pontual, exigindo a reprodução do conteúdo científico. Do outro lado, o aluno que procura se adequar às normas impostas pelo sistema escolar, memorizando os conteúdos e reproduzindo-os nas provas para obter sua promoção de uma série para outra. Os que não se enquadram ou são eliminados ou são aprovados compulsoriamente.

Nesse sentido, é fundamental que os cursos de licenciaturas levem seus alunos a compreender processos de avaliação formativa, repensando pressupostos teórico-metodológicos que contemplem as diversidades presentes na sala de aula e busquem uma pluralidade de instrumentos avaliativos (seminários, debates, estudo dirigido, discussões, atividades práticas, painel integrado, júri simulado, projetos, entre outros) em momentos diferenciados do processo de avaliação da aprendizagem.

Em seguida, os doze alunos foram convidados a participarem de um momento de reflexão sobre as respostas apresentadas e práticas vivenciadas juntamente com o professor regente da turma, com o objetivo de que esses alunos compreendessem que a avaliação da aprendizagem precisa desvincular-se do processo classificatório, seletivo e discriminatório, para estabelecer uma prática que busque analisar e refletir os resultados do processo de ensino e aprendizagem em conjunto. Desta forma, a avaliação propicia retomada de conteúdos, novas práticas e um redimensionamento de trajetória conforme a necessidade do momento, enfatizando, assim, o processo, não o produto final, refletindo o ensino que busca a construção efetiva do conhecimento.

No decorrer da discussão, relatos foram apresentados, demonstrando as habilidades construídas pelos acadêmicos em formação para a futura profissão:

"Antes do estágio supervisionado eu me encontrava aflito com o fato de entrar em uma sala de aula como professor. Não sabia se iria ter domínio de conteúdo, da classe, entre outros fatores, por este motivo "temia" estar lá na frente conduzindo os alunos. O estágio é uma oportunidade única que nos possibilita formar uma postura de professor e refletir sobre a teoria que aprendemos na universidade e a prática no dia-a-dia. Para mim o estágio foi surpreendente sendo muito mais do que eu esperava, uma experiência muito gratificante, fazendo-me confirmar minha decisão em relação a ser professor".

"O estágio é uma experiência maravilhosa, pois além de nos tornar mais humanos por conhecer as histórias dos alunos bem como suas dificuldades, não 
somente no ensino mas também em sua vida pessoal, nos permite ver na prática os nossos erros como futuros professores, além de nos permitir pensar nas formas de resolver problemas dentro da sala de aula, por exemplo, quando um aluno não compreende determinado assunto, cabe a nós professores mudar a forma de explicar, para que seja possível a compreensão de determinado conteúdo pela maioria dos alunos. [...] a troca de experiências dentro de uma sala de aula, não é somente professor-aluno, mas aluno-professor porque eles fazem com que nós aprenda com eles a dar aula, nos fazem pensar como eles, $e$ isso não somente na forma de avaliar eles, mas na forma de como transpor o conteúdo".

"Eu quando iniciei as disciplinas da área de ensino não queria de maneira alguma ser professora. Após todo o processo de formação e o desenvolvimento do estágio supervisionado pude perceber que eu gosto de ser professora, gosto tanto, que no período de regência, eu só queria elaborar minhas aulas".

Conforme os relatos acima, pode-se observar que os acadêmicos em formação inicial puderam vivenciar a realidade do seu futuro campo de atuação, experiências formativas que thes possibilitou a aquisição de diversos saberes docentes.

Na perspectiva de Tardif (2002), o saber docente é um saber plural, oriundo da formação profissional (do conjunto de saberes apresentados nas instituições de formação de professores); de saberes disciplinares (dos diversos campos do conhecimento e emergem da tradição cultural); curriculares (dos programas escolares) e experienciais (do trabalho cotidiano). Isso exige do professor capacidade de dominar, integrar e mobilizar tais saberes enquanto condição para sua prática.

Por meio do estágio supervisionado e momentos de reflexividade, pode-se observar que ocorreu uma troca de saberes entre os professores e graduandos, propiciando aos acadêmicos conviver com a realidade da prática profissional.

No decorrer das reflexões, a professora regente da turma relatou sua visão com relação as experiências vivenciadas pelos acadêmicos, conforme relato a seguir:

"Fiquei impressionada com o nível de informação que os alunos apresentaram. Conseguiram enfrentar situações que só podem ser vivenciadas na prática docente. Souberam elaborar atividades envolventes e a trabalhar com turmas cheias de particularidades, inclusive uma turma que eles trabalharam tinha nove alunos com as mais variadas dificuldades de aprendizagem (dislexia, disgrafia, hiperatividade) e somando a isso problemas sociais. Incrível a pluralidade metodológica utilizada para alcançar os alunos". 
Recorrendo aos autores Carvalho e Gil-Perez (2009, p. 71), acredita-se que "alguns obstáculos que hoje se dão na formação dos professores desaparecerão quando as vivências escolares dos futuros professores forem mais positivas".

Considerando ainda a importância da práxis na formação inicial de professores envolvendo a articulação universidade e escola e vendo nesta um campo para se promover a relação teoria e prática, consideramos o relato da professora regente da turma como sendo positiva a maneira como esse processo foi planejado, identificando na relação conjunta um caminho para a troca de experiências e enfrentamentos de dificuldades.

\section{Considerações finais}

A análise das concepções e práticas avaliativas dos acadêmicos em formação inicial evidenciou a importância de que a formação inicial do professor encontre um espaço de trocas de saberes e diálogos que possibilitem a compreensão do processo de avaliação escolar que não seja punitivo e burocrático, além de possibilitar na formação docente momentos de reflexão.

Observou-se nas análises realizadas que os instrumentos avaliativos citados não contemplavam uma pluralidade, deixando às margens do processo alunos com particularidades diversas na sala de aula.

Sendo assim, é necessário no processo de ensino e aprendizagem determinação, paciência e disposição para melhorar e, finalmente, ultrapassar os limites, com a finalidade de aperfeiçoar a transposição do conhecimento.

Por esse motivo, a avaliação da aprendizagem deve ser pensada pela comunidade escolar, buscando em conjunto uma avaliação que busque no aluno a exposição do seu ponto de vista, argumentos, seja ele a favor ou contra uma ideia, a proposição de projetos, soluções, acentuando, dessa forma, a reflexão, a participação e a criação, ou seja, a formação do sujeito que compreenda a natureza do conhecimento, valores e que, de fato, saiba se posicionar diante das circunstâncias do seu cotidiano.

Evidenciou-se que os graduandos, ao vivenciarem a experiência do estágio supervisionado, aprenderam a superar as dificuldades centrais da formação, ou seja, o desafio da reconciliação da teoria com a realidade escolar.

A partir dos dados obtidos verificou-se que os futuros professores passaram a refletir e a perceber as mudanças ocorridas na prática docente cotidiana. Desse modo, passaram a compreender a importância da troca de saberes (experienciais, curriculares e disciplinares) buscando mudar a realidade fragmentada, isolada e descontextualizada dos trabalhos até então abordados sem produzir significado para os estudantes da educação básica. 
Puderam aprimorar suas práticas metodológicas e avaliativas, tentando alcançar as diversas particularidades presentes no contexto escolar, além de compreenderem que são imprescindíveis atividades que contemplem, de forma explícita, as necessidades formativas do profissional professor em uma perspectiva de ação, reflexão e (res)significação.

\section{Referências Bibliográficas}

ANDRADE, D. P; CHINEN, U. S. R; FERREIRA, S. A. M. A importância de projetos de extensão como método de formação continuada de docentes. In: Anais do IV Seminário de Teoria e Prática de Ensino "Universidade e Escola: saberes, cultura e formação docente". XIII SEMINÁRIO DE ENCERRAMENTO DA DISCIPLINA DE PRÁTICA DE ENSINO DE EDUCAÇÃO FÍSICA, 2007.

ANDRÉ, M.E.D.A; PASSOS, L.F. Avaliação escolar: desafios e perspectivas. In: CASTRO, A.D; CARVALHO, A.M.P: Ensinar a ensinar, São Paulo: Thomson, 1998.

BASTOS, F. Formação de professores de Biologia. In: CALDEIRA, A. M. A.; ARAUJO, E. S. N. N. Introdução à didática da biologia. São Paulo: Escrituras, 2010.

BOGDAN, R; BIKLEN, S. Investigação qualitativa em educação: uma introdução à teoria e aos métodos. Porto: Porto Editor, 1991.

CASTRO, A. D. de; CARVALHO, A. M. P. de (org.). Ensinar a Ensinar. São Paulo: Pioneira, 2001.

HOFFMANN, J. Avaliar para promover: as setas do caminho. Ed. Mediação. Porto Alegre, 2001.

JUSTINA, L. A. D; FERRAZ, D. F. A prática avaliativa no contexto do Ensino de Biologia. In.: CALDEIRA, A. M. de A. ARAUJO, S.N. N. de. (org.) Introdução à didática da biologia. São Paulo: Escrituras Editora, 2009.

KRASILCHIK, M. O professor e o currículo das ciências. São Paulo: Editora Pedagógica Universitária - EPU, 1987.

LISOVSKI, L. A.; TERRAZZAN, E. A. As Instituições de Ensino Superior e as Escolas de Educação Básica na Formação Inicial dos Professores de Ciências Naturais e Biologia. In: ANAIS DO SEMINÁRIO DE PESQUISA EM EDUCAÇÃO DA REGIÃO SUL- ANPED-SUL, 6, Santa Maria: UFSM, 2006.

PIMENTA, S. G. A didática como mediação na construção da identidade do professor, uma experiência de ensino e pesquisa na licenciatura. In: André, M. E. D.; Oliveira, A. M. R. N. S. (Orgs.). Alternativas do ensino de didática. Campinas. São Paulo: Papirus, 1997. 
TERRAZZAN, E. A. As diretrizes curriculares para formação de professores da educação básica e os impactos nos atuais cursos de licenciatura. Trabalho apresentado como parte da Mesa Redonda "Diretrizes curriculares de formação de professores da educação básica: repercussões nas práticas educativas", no XI ENDIPE - ENCONTRO NACIONAL DE DIDÁTICA E PRÁTICA DE ENSINO. Goiânia, 2002.

TERRAZAN, E. A.; Schmidt, I. P.; Azevedo, M. A. R. Concepções e práticas presentes em escolas de Ensino médio sobre aspectos envolvidos na formação de professores In: Selles, S.E., Ferreira, M. S.; Vilela, M. L. (Orgs.). Prática de Ensino: memórias em tempos de mudanças. Coletânea da VI Escola de Verão para professores de prática de Ensino de Biologia, Física, Química reas Afins. Período de 3 a 6 de Novembro de 2003, Niterói/RJ/BRA: UFF. 12 p.(CD-Rom, 85-88578-03-4, arq<CO/PQ_23.pdf >), 2003.

Anelize Queiroz Amaral. Doutoranda do Programa de Pós- graduação em Educação (Unesp); Professora assistente do Curso de Ciências Biológicas da Universidade Tecnológica Federal do Paraná - UTFPR. any qa@hotmail.com

Kassiana Miguel. Mestranda em Educação Científica e Tecnológica da Universidade Federal de Santa Catarina - UFSC. kassianamiguel@hotmail.com

Tais Regina Cutchma. Licenciada em Ciências Biológicas pela Universidade Tecnológica Federal do Paraná - UTFPR. Tais.cutchma@hotmail.com

Débora Daneluz. Licenciada em Ciências Biológicas pela Universidade Tecnológica Federal do Paraná - UTFPR. deboradaneluz@hotmail.com

Lucas Battisti. Licenciado em Ciências Biológicas pela Universidade Tecnológica Federal do Paraná - UTFPR. lucasbattisti@hotmail.com

Alexandre Augusto Auache Filho. Graduando em Ciências Biológicas pela Universidade Tecnológica Federal do Paraná - UTFPR. alexandreauacheutfpr@outlook.com 